Himat Vaghadia MB FRCPC MHSc, Paul Kapnoudhis MD, Leonard C. Jenkins BA MD FRCPC, David Taylor MD FRCS*

\section{Continuous lumbosacral block using a Tuohy needle and catheter technique}

Il n'y eu aucun effet secondaire. Cette technique est efficace et est recommandée lorsqu'une anesthésie unilatérale du membre inférieur est désirée et qu'une anesthésie sous-arachnoïdienne ou épidurale est contre-indiquée. lumbar and sacral plexuses. A 17-gauge Tuohy needle was positioned between the transverse processes of $L_{4}$ and $L_{5}$ and an epidural catheter inserted into the space between the quadratus lumborum and psoas muscles. Forty to seventy millilitres of local anaesthetic were injected and resulted in good surgical anaesthesia within 12-20 min. Radiographic studies in these patients confirmed placement of the catheter in close proximity to the lumbosacral plexus. Experience in a further 12 cases is also reported. There were no side-effects. The technique is successful and is recommended when unilateral lower limb anaesthetic is required and when spinal and epidural anaesthesia are contraindicated.

Il s'agit de trois cas chez qui un bloc lombosacré continu a été réalisé à l'aide d'un cathéter et d'une aiguille épidurale. Une bonne anesthésie chirurgicale a été obtenue de façon unilatérale aux membres inférieurs dans les trois cas, avec un bloc réussi des plexus lombaires et sacrés. Une aiguille Tuohy $17 G$ a été insérée entre les apophyses transverses de $L_{4}$ et $L_{5}$ et un cathéter épidural inséré dans l'espace entre le carré des lombes et le muscle psoas. Quarante à $70 \mathrm{ml}$ d'anesthésique local ont été injectés et ont donné une bonne anesthésie chirurgicale en 12 à 20 minutes. Des études radiographiques chez ces patients ont confirmé la localisation du cathéter très près du plexus lombosacré. Des résultats chez 12 autres cas sont également rapportés.

\section{Key words}

ANAESTHETIC TECHNIQUES: regional, lumbar plexus.

From the Departments of Anaesthesia and Surgery, ${ }^{*}$ Vancouver General Hospital, The University of British Columbia, Vancouver, British Columbia.

Address correspondence 10: Dr. Himat Vaghadia, Department of Anaesthesia, Faculty of Medicine, The University of British Columbia, Room $3200-910$ West 10th Avenue, Vancouver, B.C. V5Z 4E3.

Accepted for publication 12th August, 1991.
The technique of posterior lumbosacral blockade is well described. ${ }^{1,2}$ It is recommended for unilateral lower extremity surgery. However, the traditional technique suffers from some disadvantages. Firstly, it relies upon the use of a nerve stimulator or elicitation of paraesthesia. Secondly, where surgery is prolonged, intraoperative "top-ups" are not possible. Thirdly, blockade of the sacral plexus may not be produced. ${ }^{3}$ Any technique that helps to overcome these disadvantages would be desirable. We report a modification of the single-injection technique described by Winnie. ${ }^{1,4}$ In our modification, a teflon (epidural) catheter introduced through a Tuohy needle was placed into the psoas compartment to allow repeated "topup" injections and facilitate sacral plexus blockade.

\section{Case reports}

\section{Case \#I}

A 75-yr-old $70 \mathrm{~kg}$ woman, height $153 \mathrm{~cm}$, presented for arthroscopy of the left knee. Her medical history was unremarkable. She agreed to have surgery with regional and her back was cleaned with betadine. The site for needle insertion was identified using the landmarks described by Winnie ${ }^{1,4}$ (the intersection of the intercristal line and a line drawn parallel to the spine through the posterior superior iliac spine). A 17-gauge Tuohy needle was advanced perpendicular to the coronal plane between the transverse processes of $\mathrm{L}_{4}$ and $\mathrm{L}_{5}$ to the fascia iliaca on the anterior surface of the quadratus lumborum. A 5-mL glass syringe containing saline was attached to the epidural needle and a loss of resistance technique was used during needle advancement. ${ }^{2}$ Entry of the needle tip into the potential space between the quadratus lumborum and psoas muscle was accompanied by a slight click as well as loss of resistance. Paraesthesiae were not elicited and anaesthesia. She was placed in the right lateral position 
stimulation with a nerve stimulator did not produce twitching of the psoas, quadratus lumborum or other lower limb muscles. A radio-opaque epidural catheter was easily advanced $8 \mathrm{~cm}$ caudad without fluoroscopy and then taped in position. A test dose of $3 \mathrm{ml}$ local anaesthetic (chloroprocaine 3\% with epinephrine $1: 200,000$ ) was injected through the catheter followed by the remaining $27 \mathrm{ml}$ of local anaesthetic.

The patient was then turned to the supine position and sedated with midazolam (total dose $3.5 \mathrm{mg}$ ) and fentanyl $50 \mu \mathrm{g}$. The patient was allowed to breathe room air for the duration of the operation because her oxygen saturation remained unchanged at $97 \%$. A further $40 \mathrm{ml}$ of local anaesthetic (lidocaine $1.5 \%$ with epinephrine 1:200,000) was injected ten minutes after the start of surgery because of inadequate anaesthesia. The patient had sensory block of the $L_{2}-L_{5}$ and $S 1$ dermatomes within ten minutes of the second injection. In addition, she was unable to plantarflex or dorsiflex the foot, extend the knee or flex the hip. The patient tolerated the $60 \mathrm{~min}$ procedure well and was painfree in the recovery room one hour later. Abdominal $x$-ray in the recovery room confirmed that the catheter was in the paraspinal position with its tip at the $\mathrm{L}_{5}$ level.

\section{Case \#2}

An 88-yr-old, $54 \mathrm{~kg}$ woman, height $145 \mathrm{~cm}$, presented for left above knee amputation. Her main medical problems were diffuse arteriopathy with ischaemia of the left leg, hypertension, left ventricular hypertrophy with strain, atrial fibrillation, arthritis, cachexia and peptic ulcer disease. Continuous lumbosacral block was performed using the technique described for patient \#1. A nerve stimulator was not used and paraesthesiae were not obtained. Chloroprocaine $2 \%(40 \mathrm{ml})$ and bupivacaine $0.5 \%$ with epinephrine $1: 200,000(15 \mathrm{ml})$ were injected via an epidural catheter. She was not given any sedatives and oxygen $\left(8 \mathrm{~L} \cdot \mathrm{min}^{-1}\right)$ was administered by face mask. She tolerated the 90-min procedure well but complained of some discomfort when the sciatic nerve was being sectioned. This discomfort was successfully treated with $\mathbf{3 0}$ $\mathrm{mg}$ ketamine $i v$ and a top-up of $5 \mathrm{ml}$ chloroprocaine $3 \%$ via the lumbosacral catheter. In the recovery room, contrast solution $(20 \mathrm{ml})$ was injected via the catheter to identify its position. The catheter tip lay over the left sacro-iliac joint with contrast solution spreading upwards to the origins of the psoas and descending with the muscle into the pelvis (Figure).

\section{Case \#3}

A 77-yr-old, $63 \mathrm{~kg}$ man, height $157 \mathrm{~cm}$ was scheduled for debridement of the right leg and harvesting of skin graft from the right thigh. Principal preoperative findings were chronic obstructive pulmonary disease, diabetes mellitus,

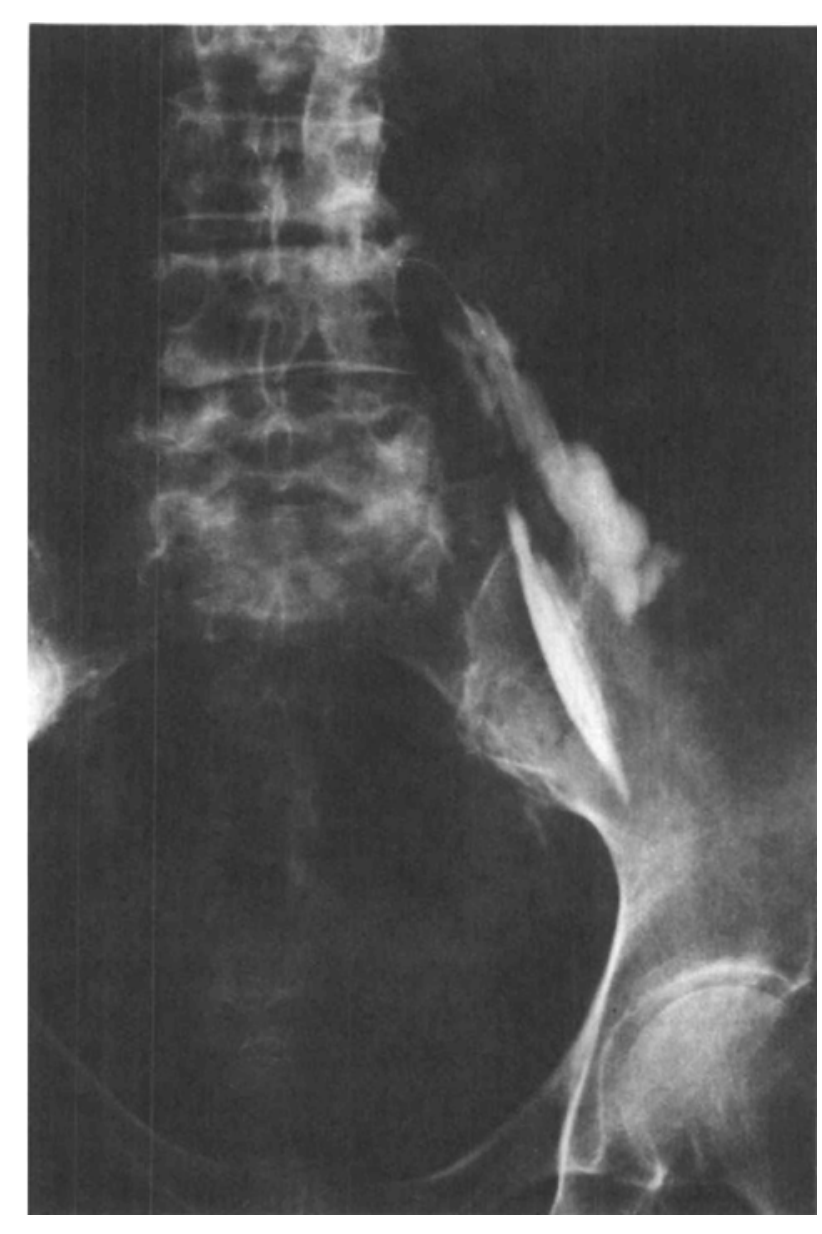

FIGURE An A-P view of the injection of $20 \mathrm{ml}$ contrast medium into the psoas compartment of case 2 . The contrast is seen spreading upwards to the origins of the psoas $\left(\mathrm{L}_{2}-\mathrm{L}_{5}\right)$ and descending with the muscle into the pelvis.

nephropathy, peripheral vascular disease and controlled heart failure. Anaesthesia was established using the continuous lumbosacral block technique described for patient \#1. Chloroprocaine $3 \%(20 \mathrm{ml})$ and bupivacaine $0.5 \%$ with $1: 200,000$ epinephrine $(20 \mathrm{ml})$ were administered via the epidural catheter and resulted in complete block of $L_{2}-L_{5}$ and $S 1$ dermatomes. The patient tolerated the $90 \mathrm{~min}$ procedure without requiring sedatives. In the recovery room injection of contrast solution $(30 \mathrm{ml})$ confirmed that the catheter tip was at the level of $L_{5}$ with contrast solution spreading more extensively than was the case with patient \#2 described above.

\section{Discussion}

Two principal techniques have been described for posterior lumbar plexus blockade. With the psoas sheath block (PSB) technique, a needle is inserted $3-4 \mathrm{~cm}$ lateral to the spinous process of $L_{3}$, is passed caudad to the transverse 
process of $\mathrm{L}_{3}$ and advanced $1.5-2 \mathrm{~cm}$ beyond the transverse process. ${ }^{3}$ The needle is now within the psoas sheath and local anaesthetics injected here will block the nerves of the lumbar plexus as they lie within the body of the psoas muscle.

An alternative technique is the psoas compartment or lumbosacral block (LSB). ${ }^{1.2}$ At the level of $\mathrm{L}_{4-5}$ the nerves of the lumbar plexus emerge from the psoas muscle and lie in a fascial compartment between the psoas and quadratus lumborum muscles. Local anaesthetics injected into the potential space between these two muscles at this level should bathe the lumbar and possibly the sacral plexus. With Chayen's approach, a 22-gauge, 31/2 inch spinal needle is inserted perpendicular to the coronal plane at a point $3 \mathrm{~cm}$ caudad to the intercristal line and $4-5 \mathrm{~cm}$ lateral to the midline. If the transverse process of $L_{5}$ is encountered, the needle is redirected cephalad to it. ${ }^{2}$ Winnie's description positions the needle tip in about the same location - approximately $4-5 \mathrm{~cm}$ from the midline between the transverse processes of $L_{4}$ and $L_{5}$. A loss of resistance technique may be of help in confirming passage of the needle tip through the anterior fascia of the quadratus lumborum. ${ }^{2}$ Confirmation of the needle placement in the plexus requires the use of a peripheral nerve stimulator.

The success rate of these two techniques (PSB and LSB) was found to be similar (PSB: 1/25 failure, LSB: $2 / 25$ failure). ${ }^{3}$ However, neither produced blockade of the sacral plexus. A nerve stimulator was used for precise needle placement for both techniques. These findings are interesting since Winnie maintains that with his technique, $40 \mathrm{ml}$ of local anaesthetic injected after eliciting a paraesthesiae will block both the lumbar and sacral plexuses ${ }^{4}$ but this has not been substantiated.

Recently, a case report utilising a psoas catheter technique was described. ${ }^{5}$ The authors used a peripheral nerve stimulator and landmarks similar to that of Chayen. ${ }^{2}$ A 16gauge Secalon central venous catheter was prepared by inserting the metal needle of a 20 -gauge Venflon intravenous (Viggo) catheter into the proximal end of the larger metal needle in the Secalon's hub. After satisfactory needle positioning, the central venous catheter was advanced beyond the needle and local anaesthetic solution injected through the catheter. The extent of block achieved by this technique was not described but probably did not involve the entire lumbosacral plexus because the patient also required thiopentone and $60 \%$ nitrous oxide for surgery. The position of the catheter was also not assessed radiologically.

Although the use of an epidural catheter technique has been described for the performance of continuous brachial plexus block ${ }^{6}$ and continuous lumbar sympathetic block, we are unaware of reports where continuous lumbosacral
TABLE Summary of 12 patients who were administered continuous lumbosacral block anaesthesia. (Total volume of local anaesthetic used was $40-50 \mathrm{ml}$ per patient)

\begin{tabular}{|c|c|c|}
\hline Site of operation & $\begin{array}{l}\text { No. of } \\
\text { cases }\end{array}$ & Comments \\
\hline Arthroscopy & 3 & Successful block \\
\hline Achilles tendon repair & 2 & Successful block \\
\hline Above knee amputation & 3 & $\begin{array}{l}\text { Ketamine iv for discomfort } \\
\text { when sciatic nerve sectioned } \\
\text { in case: abnormal PT in } 1 \\
\text { case }\end{array}$ \\
\hline Below knee amputation & 1 & Successful block \\
\hline $\begin{array}{l}\text { Repair false aneurysm } \\
\text { femoral artery }\end{array}$ & 2 & Successful block \\
\hline $\begin{array}{l}\text { Debridement leg and } \\
\text { ligation bleeding } \\
\text { vein graft }\end{array}$ & 1 & $\begin{array}{l}\text { Ketamine supplementation } \\
\text { was required, PT abnormal }\end{array}$ \\
\hline Total & 12 & \\
\hline
\end{tabular}

block has been achieved with an epidural catheter technique.

Our technique utilises the landmarks described by Winnie ${ }^{1,4}$ but differs from Winnie's method in not eliciting parasthaesiae. This may be an advantage since needleinduced parasthaesiae have been implicated in postoperative neurological sequelae. ${ }^{8}$ In addition the technique may be used in patients with language difficulties and in sedated patients where it may be difficult to determine if parasthaesiae have occurred.

It has been suggested that the use of a nerve stimulator for lumbosacral block may improve the block success rate particularly if a sheathed needle is also used. ${ }^{3}$ Our experience with these three patients and a further 12 cases (Table) suggest that this may not be the case. In addition, the use of relatively large volumes of local anaesthetics with the ability for further top ups, may help to increase the success rate. The importance of volume in determining block success is also confirmed by our roentgenographic studies in patients \#2 and \#3. A larger volume of contrast was injected in patient \#3 and its spread was more extensive.

The volume of local anaesthetic used was much higher than recommended ${ }^{2.4}$ in our first two cases probably due to our inexperience with the technique. In subsequent cases volumes of 40 to $50 \mathrm{ml}$ of local anaesthetic were usually adequate if one is prepared to wait between 12-20 min for good surgical anaesthesia. We would caution against using volumes of local anaesthetic in excess of those recommended for this technique, ${ }^{2.4}$ due to the potential for systemic toxicity.

Anaesthetists should also be aware of the risk of inadvertent epidural blockade when performing lumbosacral blockade. Although the exact mechanism for this phenom- 
enon has not been established the risks of epidural blockade appear to be higher when lumbosacral trunk stimulation is used as an endpoint for needle placement. ${ }^{3}$

Based on our experience and a review of the literature, we would suggest that the continuous lumbosacral blockade should be considered in those patients where spinal and epidural anaesthesia are contra-indicated and when unilateral lower extremity anaesthesia is required. In addition, it is a useful method of producing continuous postoperative analgesia. There is as yet incomplete information on the use of this technique in patients receiving anticoagulant therapy and this needs further investigation. We have used continuous lumbosacral block anaesthesia in two patients receiving anticoagulants without complications.

In summary, we report a technique of continuous posterior lumbosacral plexus block suitable for intraoperative anaesthesia and postoperative analgesia. The technique uses equipment readily available to anaesthetists (an epidural needle and catheter). It does not require elicitation of paraesthaesiae or the use of a nerve stimulator. It has the advantage of blocking the lumbar plexus as well as the sacral plexus and for facilitating intraoperative and postoperative "top ups."

\section{References}

1 Winnie AP, Ramamurthy S, Durrani Z, Radonjic R.

Plexus blocks for lower extremity surgery, Anesthesiology

Review 1974; 1: 11-6.

2 Chayen D, Nathan $H$, Chayen $M$. The psoas compartment block. Anesthesiology 1976: 45: 95-9.

3 Parkinson SK, Mueller JB, Little WL, Bailey SL. Extent of blockade with various approaches to the lumbar plexus. Anesth Analg 1989; 68: 243-8.

4 Winnie AP. Regional anaesthesia for the extremities. ASA Refresher Course Lectures 1985; 254: 1-5.

5 Bruce BD. Lee E, Croitoru $M$. Psoas block for surgical repair of hip fracture: a case report and description of a catheter technique. Anesth Analg 1990; 71: 298-301.

6 Plancarte R, Amescua C, Marron M, San Miguel P, Aldrete $J A$. Continuous brachial plexus block introducing catheters through a Tuohy needle in the axilla. Anesthesiology 1987; 67: A287.

7 Parkinson SJ, Mueller JB. A simple technique for continuous lumbar sympathetic blockade. Anesth Analg 1989; 68: $\$ 218$.

8 Selander $D$, Dhuner $K$, Lundborg G. Peripheral nerve injury due to injection needles used for regional analgesia. Acta Anaesthesiol Scand 1977; 21: 182-8. 